\title{
O QUE A ENFERMEIRA DA SECRETARIA DE SAÚDE VEM FAZENDO PELO ESCOLAR
}

\author{
Maria Célia Pinheiro de Melo Vilar, Maria das Graças Queiroz Maranhão², \\ Mary Braga de Lima ${ }^{3}$
}

VILAR, M. C. P. de M. et alii O que a enfermeira da Secretaria da Saúde vem fazendo pelo escolar. Rev. Bras. Enf., Brasília, 37(1): 56-64, 1984.

\begin{abstract}
RESUMO. As autoras descrevem como enfermei ras professoras escolares e respectivos pais vêm se articulando num trabalho para a saúde, visando a melhoria das condições de vida da comunidade, através da participação consciente e crítica, do diagnóstico das necessidades e da busca de soluções alternativas para resolver os problemas detectados. Apontam as dificuldades de articulação com os serviços de saúde e mostram as experiências dos grupos de saúde e encontros de avaliação numa metodologia participativa.
\end{abstract}

ABSTRACT. The authors describe how nurses teachers students and parents are doing health work in order to encrease life's conditions in a community. They develop concious and critical participation, diagnosis of needs and alternative solutions to solve detected problems. They show difficulties with health service, their experience as a member of this group and an evaluation done using participant methodology.

\section{INTRODUÇÃO}

Estudos realizados em termos de grupos comprovam a preponderância na troca de experiências e solução de problemas entre iguais $^{5}$. O programa "Criança para Criança" sugere atividades realizáveis por orientação de outra criança com a finalidade de ensinar e incentivar naquilo que diz respeito ao bem estar ${ }^{1}$.

A transferência de conhecimento dá-se quando o conhecimento ou habilidade adquirida no assunto é assimilada de modo a modificar o comportamento e existe um realce, quando este comportamento tende a influenciar outras pessoas ${ }^{9}$. Se o escolar estimula os bons hábitos de higiene em sua família, está transferindo a aprendizagem recebida na escola aos demais membros do domicílio.

Os professores facilitam o processo ensino-aprendizagem, procurando relacionar aquilo que ensinam, com assuntos que dizem respeito à saúde, dentro da realidade da comunidade.

Considerando aspectos do desenvolvimento mental, sabe-se que na criança até os sete anos, o pensamento é concreto e ela ainda não consegue fazer ou compreender abstração ${ }^{5,10}$.

Sabe-se também que a partir dos sete anos a criança entra na fase que se caracteriza por obter satisfação nas atividades escolares, entra no estágio da reflexão, começa a aquisição de conceitos abstratos. Adquirem importância os jogos, os grupos, porque o dinamismo que distingue essa idade mostra a criança em permanente atividade ${ }^{10}$.

São esses fatos ratificados pelas modernas teorias de aprendizagem que elegem as atividades desenvolvidas na escola, como o melhor caminho para estimulação dos processos mentais superiores na criança a partir da atividade lúdica, da observação e relacionamento de fatos, assim como o estímulo e manutenção das relações sociais ${ }^{5,10}$.

A observação de fatos relacionados a modos de morar e modos de conviver e o relacionamento desses fatos à saúde/doença levará a quantos se envolvam no processo a assumirem hábitos globais favoráveis à saúde individual, familiar e grupal ${ }^{3}$.

Somente com a participação em termos

1. Enfermeira Sanitarista, Coordenadora do Programa de Educação para a Saúde, Secretaria de Saúde do Estado do Ceará. COREn-CE 9158.

2. Enfermeira de Saúde Pública, Supervisora do Programa de Educação para Saúde, Secretaria de Saúde do Estado do Ceará. COREn-CE 19583.

3. Enfermeira especialista em Saúde Pública, Orientadora do Programa de Educação para Saúde, Secretaria de Saúde do Estado do Ceará. COREn-CE 18624. 
críticos, a comunidade será capaz de optar e decidir por melhores condições de vida ${ }^{11,15}$.

A ação educativa do Programa de Educação em Saúde se faz necessária plos aspectos de, eficiência e eficácia (baixo custo), além de contar com o envolvimento da comunidade, que passa a ser o agente catalizador do processo educativo em saúde".

As ações de saúde dentro dos esforços de ampliação de cobertura às populações carentes caracterizam-se:

- Por maior ênfase nas ações de prevenção primária;

- Pela utilização de pessoal de nível médio e elementar treinados e supervisionados; tária.

- Pelo incentivo à participação comuni-

O nível de saúde dessas populações evidencia-se nos altos índices de morbi-mortalidade infantil, sendo que o grupo de zero a quatro anos, concentra mais de $50 \%$ de todos os óbitos. As principais causas são as doenças infecciosas, controláveis através de vacinação, saneamento básico e as controláveis pelo diagnóstico precoce e tratamento oportuno. Dos 30.307 óbitos ocorridos em Fortaleza no período de $1978-80,49,5 \%$ deu-se com o grupo de zero a quatro anos, $1,2 \%$ com o grupo de cinco a nove anos e $1,4 \%$ com o grupo de dez a catorze anos ${ }^{7,16}$.

A mortalidade proporcional em Fortaleza não apresenta uma evolução satisfatória para o grau de desenvolvimento a que aspiramos. $\mathrm{O}$ risco de morrer entre menores de um ano é bem mais representativo diante das demais idades. Isto mostra que Fortaleza encontra-se com um baixo nível de saúde ${ }^{7,16}$.

Baseado nestes fatos a solução proposta é ativar a escola como ponto de partida, para a extensão à família e a comunidade em geral, através da ação educativa em saúde (mantendo a unidade sanitária como estrutura de apoio), com o fito de:

- Formar bons hábitos para a promoção e preservação da saúde individual e comunitária;

- Envolver a rede escolar como apoio ao processo de mudança de atitude frente à saúde;

- Integrar as Secretarias de Saúde e de Educação aos órgãos governamentais, que já atuam, direta ou indiretamente, no campo da saúde.

\section{DESENVOLVIMENTO}

Partindo da premissa que a escola funciona como agente nucleador das ações de edu- cação, as enfermeiras da Secretaria de Saúde do Estado do Ceará, elaboraram o Programa de Educação em Saúde Escolar/ComunitáriaPRESCE, baseado nos resultados dos encontros realizados em algumas unidades escolares, com o objetivo de detectar as necessidades da escola com relação à saúde.

Para facilitar o trabalho, foi realizado o levantamento sócio-sanitário da área a ser trabalhada e esta área foi dividida em sete módulos. Denominou-se de módulo uma localidade geograficamente definida, contendo dentro de seus limites e próximos uns dos outros, instituições sociais e sanitárias de fácil acesso à população ali residente, devendo haver algumas unidades escolares e um centro de saúde do Estado.

Com o propósito de melhor operacionalizar o Programa, formou-se uma equipe central que coordena, supervisiona e avalia as ações desenvolvidas em cada módulo (centro de saúde e unidades escolares). $O$ centro de saúde, através da enfermeira, pode coordenar a ação a nível de unidade escolar, contando com a ajuda de bolsistas - estudantes de enfermagem e serviço social - que, após uma seleção baseada em disciplinas cursadas e disponibilidade de tempo, recebem um treinamento de educação para saúde (Vide fluxograma).

Urge informar que nem todos os centros de saúde estão envolvidos no processo de coordenação a nível de unidade escolar, limitando-se a atender à demanda advinda da escola.

Pode-se afirmar que o ano de 1979 caracterizou-se pela elaboração do ante-projeto e divulgação oral e escrita do PRESCE, de forma a oportunizar ampla discussão e reformulações.

No ano de 1980 , iniciou-se o processo de implantação do Programa com a mobilização e treinamento de diretores, supervisores, orientadores educacionais e professores do primeiro grau - séries iniciais, perfazendo um total de 2.000 treinandos de 72 escolas, com o objetivo de torná-los agentes multiplicadores das ações básicas de educação em saúde, não somente junto ao escolar como também aos seus familiares.

Compreende-se saúde como "modo de morar e de conviver, modo de sentir e ver as coisas e não simplesmente a memorização de conceitos sobre aspectos de saúde-doença"3. Essa filosofía projeta-se na programação e execução do treinamento que é dividido em três partes:

$\mathrm{Na}$ primeira, discutem-se a partir da realidade de vida e experiência profissional, os conceitos de saúde-doença como um processo 


\section{FLUXOGRAMA}

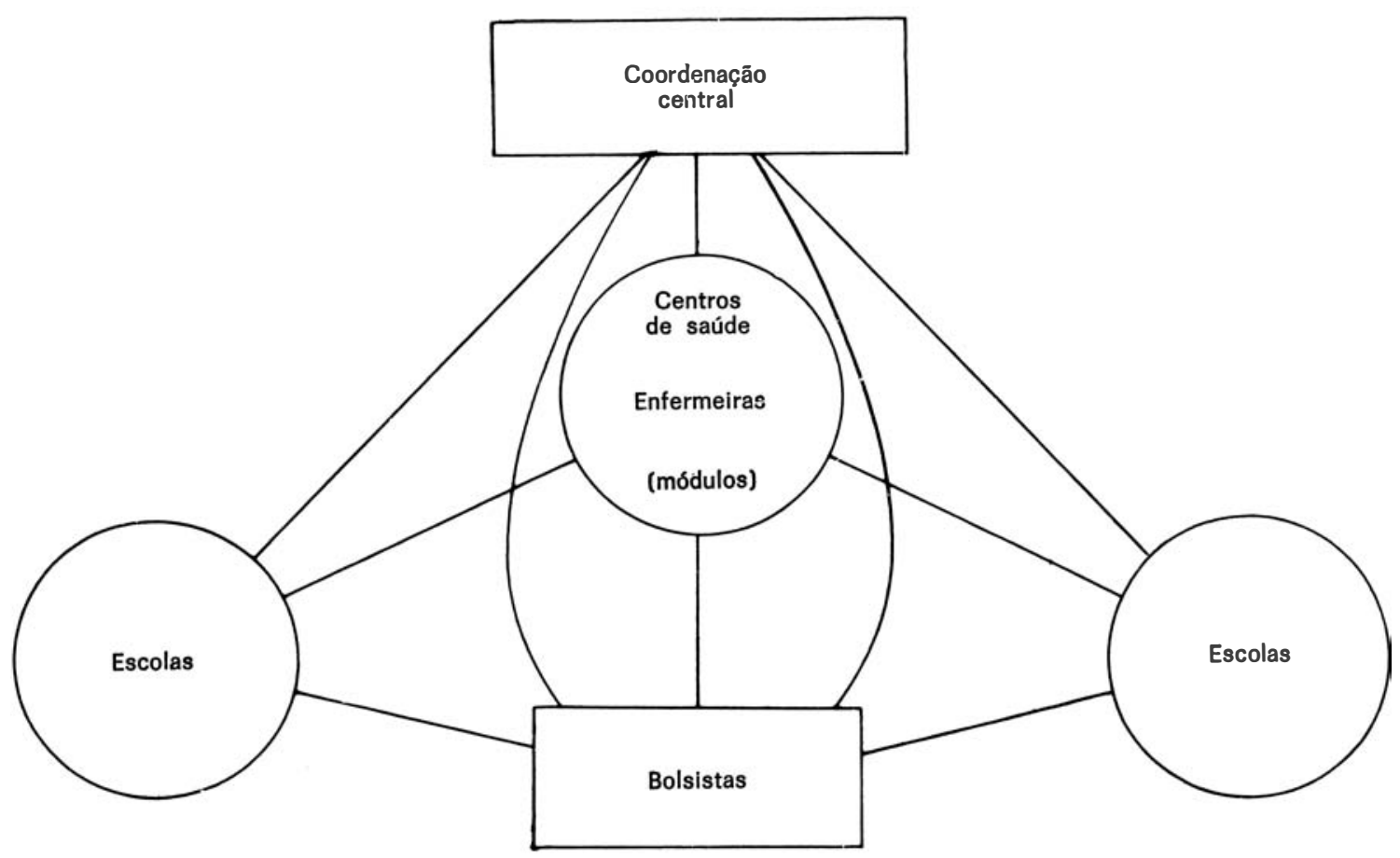

de equilíbrio dinâmico entre o homem (com todos os seus mecanismos de defesa) e os fatores agressivos do meio. $\mathrm{O}$ objetivo é estimular hábitos de vida saudáveis quer individuais, quer grupais: esporte, vida ao ar livre, cuidados com a água, lixo, dejetos, etc.

$\mathrm{Na}$ segunda parte, a professora adquire habilidades para realizar exame antropométri$\mathrm{co}$, verificar acuidade visual e auditiva, promover e identificar postura e mecânica corporal corretas e encaminhar os casos desviantes da faixa de normalidade. Aprende como prevenir acidentes e prestar socorros de urgência.

$\mathrm{Na}$ terceira parte, a professora é orientada para montar o banco de informação sobre saúde, organizar e implementar o grupo de saúde (através de atividades) e integrar conceitos de saúde às diversas disciplinas do currículo escolar.

Não se pode separar por ano as etapas que sucederam ao treinamento, quando entende-se educação em saúde como um processo, pois algumas escolas galgam estágios de auto-determinação antes de outras; pode-se ainda considerar a grande extensão da área do Programa, que torna a realidade da comunidade escolar diferente de um módulo para outro ${ }^{8}$.

Os anos de 1981 a 1982, caracterizaram- se pela implantação e implementação das ações de Educação em Saúde nas escolas.

Livros, álbuns seriados, jogos, "folders" foram elaborados com o fito de dar apoio às atividades de educação em saúde desenvolvidas na escola. Este material, de linguagem clara e acessível aos escolares, faz parte do acervo da escola e unidade de saúde.

\section{ATIVIDADES QUE VEM SENDO REALIZADAS DESDE 1981 POR PROFESSORES, ESCOLARES E FAMILIARES}

No início de cada semestre, reunem-se professores e enfermeira na unidade escolar, para identificar as necessidades sentidas pelo corpo docente e planejar as ações a serem desenvolvidas. Dentre elas pode-se citar:

\section{Introdução de conceitos básicos de saúde no currículo escolar}

A enfermeira orienta os professores durante o planejamento, para que sejam introduzidas em cada disciplina do currículo básico, noções de educação em saúde, com a finalidade de reforçar a aprendizagem em saúde. 


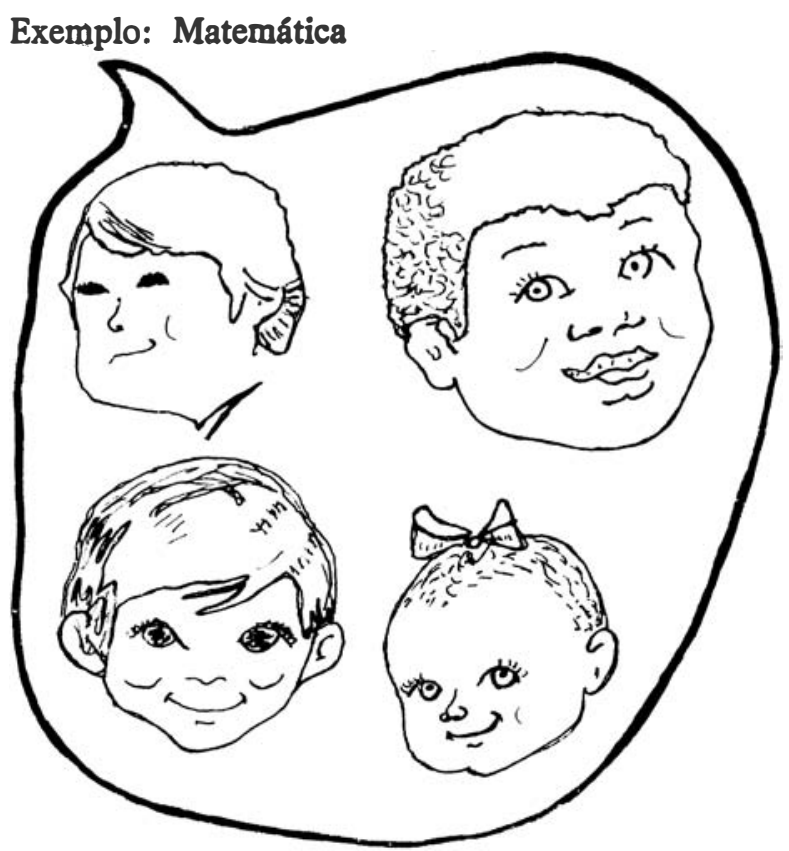

O conjunto "A" é o conjunto de crianças vacinadas contra a tuberculose.

O conjunto "B" é o conjunto de crianças não vacinadas.

$\mathrm{O}$ que falta às crianças do conjunto " $\mathrm{B}$ " para pertencerem ao conjunto " $\mathrm{A}$ "?

Observação: A professora aproveita a oportunidade e mostra para os escolares a proteção que têm as crianças do conjunto " $\mathrm{A}$ " e o perigo em relação à doença que correm as do conjunto "B". Incentiva-os a procurar os serviços de saúde a fim de, após imunizados, pertencerem todos ao conjunto " $\mathrm{A}$ ".

\section{Grupo de saúde}

Grupo de saúde é a reunião associativa de escolares com a finalidade de influir favoravelmente nos hábitos, atitudes e conhecimentos referentes à saúde. $\mathrm{O}$ grupo de saúde fazse presente pela ação de seus associados nas múltiplas atividades da escola a que pertencem ${ }^{5}$.

O corpo docente deverá ser preparado para organizar o grupo de saúde e mantê-lo dinâmico durante todo o ano.

Dependendo das atividades a serem desenvolvidas pelo grupo de saúde, ministra-se pequenos cursos de educação em saúde (prevenção de acidentes e socorros de urgência, higiene pessoal, doenças transmissíveis, etc.), para que os escolares possam repassar estes conhecimentos entre os colegas, familiares e vizinhança.

Em muitos escolares já se observam mudanças de hábitos e atitudes com relação à

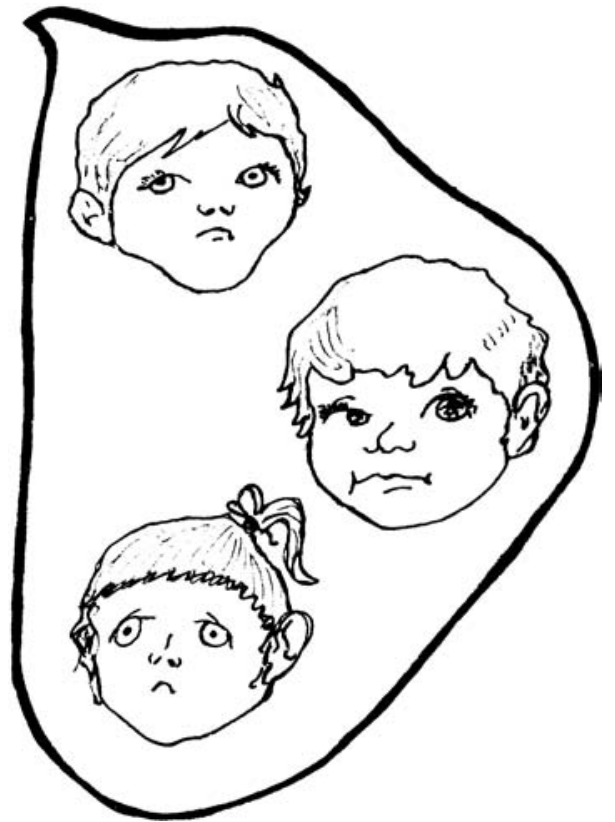

saúde, principalmente nos escolares que participam dos grupos de saúde.

\section{Banco de informação sobre saúde}

Os escolares elaboram perguntas sobre saúde/doença e depositam numa urna. A professora, juntamente com a enfermeira, classifica as perguntas por assunto e, um dia na semana, tenta abordar aquele assunto com os escolares. As perguntas com respectivas respostas são fichadas e arquivadas na biblioteca para serem relidas em outra oportunidade. Algumas perguntas elaboradas são transformadas em casos e discutidos nos encontros de pais, ocorrendo assim um reforçamento da orientação dada pela professora. Esta atividade dá mais condições de programar sessões educativas baseadas nas necessidades sentidas pelos escolares.

\section{Vacinação}

Levando-se em conta que a vacina BCG deve ser administrada na faixa etária de zero a catorze anos e, a vacina anatox-tetânico deve ser dada em três doses, quando não for aplicada a DPT nos quatro primeiros anos de vida, considera-se prioritário o uso destas duas vacinas pelos escolares de primeiro grau séries iniciais. Atribui-se também causas de caráter sócio-cultural a esta prioridade, tais como a endemicidade da tuberculose nas áreas periféricas onde o programa atua e o grande número de acidentes que ocorrem tanto nas escolas como nas residências, sem que medidas 


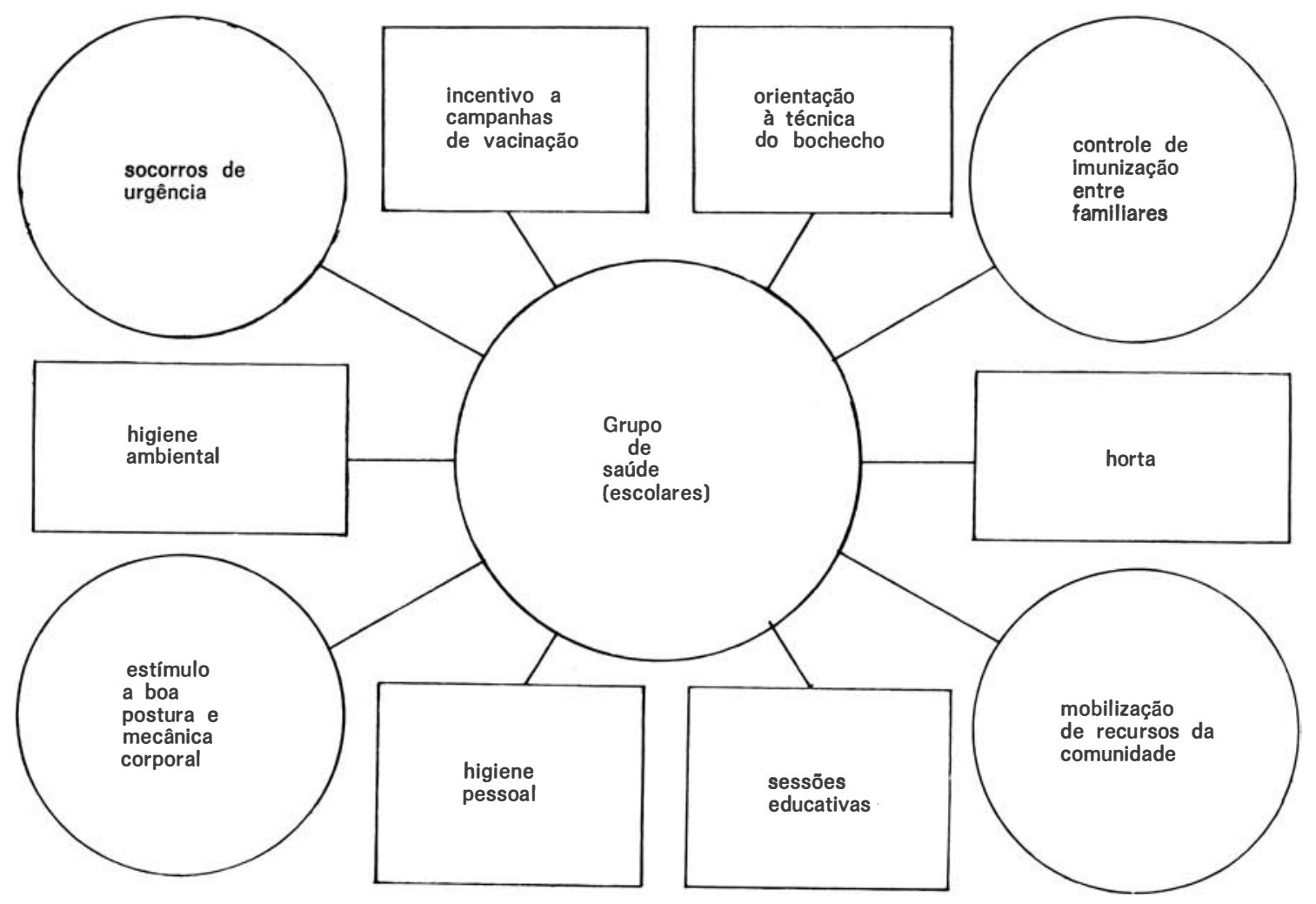

profiláticas necessárias sejam tomadas, no sentido de prevenir o tétano.

Sabendo-se da rejeição que os escolares têm normalmente com relação às vacinas, faz-se previamente sessões educativas, com 0 intuito de provocar mudanças, quanto à aceitação e quanto ao reconhecimento pelo próprio escolar, da importância das vacinas na prevenção das doenças. Vale ressaltar a colaboração prestada pelo grupo de saúde quando promove concurso de cartazes e exposição oral sobre o assunto.

\section{Bochecho com fluor}

Para aplicação de bochecho com fluor em escolares, tem-se feito um trabalho de conscientização junto ao corpo docente e discente, e pais de escolares.

Os professores, após serem treinados para desenvolver a técnica de aplicação do bochecho, promovem sessões educativas sobre técnica de escovação e importância do bocheho com fluor na prevenção da cárie dentária.

\section{Reunião com pais}

O objetivo primordial do PRESCE com relação aos pais é realizar reuniões participati- vas para discutir problemas de saúde detectados entre os escolares.

Vale ressaltar que nestas reuniões, a enfermeira integra o saber popular dos pais ao saber técnico, num processo educativo, para que estes percebam a realidade em que vivem e adquiram uma consciência crítica em busca da saúde de seus familiares.

\section{Acuidade visual e auditiva}

A visão e audição do escolar merecem atenção especial por parte dos professores. $\mathrm{O}$ olho e o ouvido acometidos por afecções prejudicam, com maior freqüência, a aprendizagem e o desenvolvimento da criança. Os malefícios decorrentes dos defeitos da visão e/ou audição podem ser diminuídos ou evitados, muitas vezes, quando cedo identificados.

Os professores são orientados para descobrir afecções contagiosas e verificar a acuidade visual e auditiva dos escolares, tendo o cuidado de questionar com eles a finalidade e a importância dos resultados do exame para a promoção da saúde.

Antes de realizar os exames, o aluno é preparado com a intenção de reduzir o nível de ansiedade e cooperar na hora dos exames. 


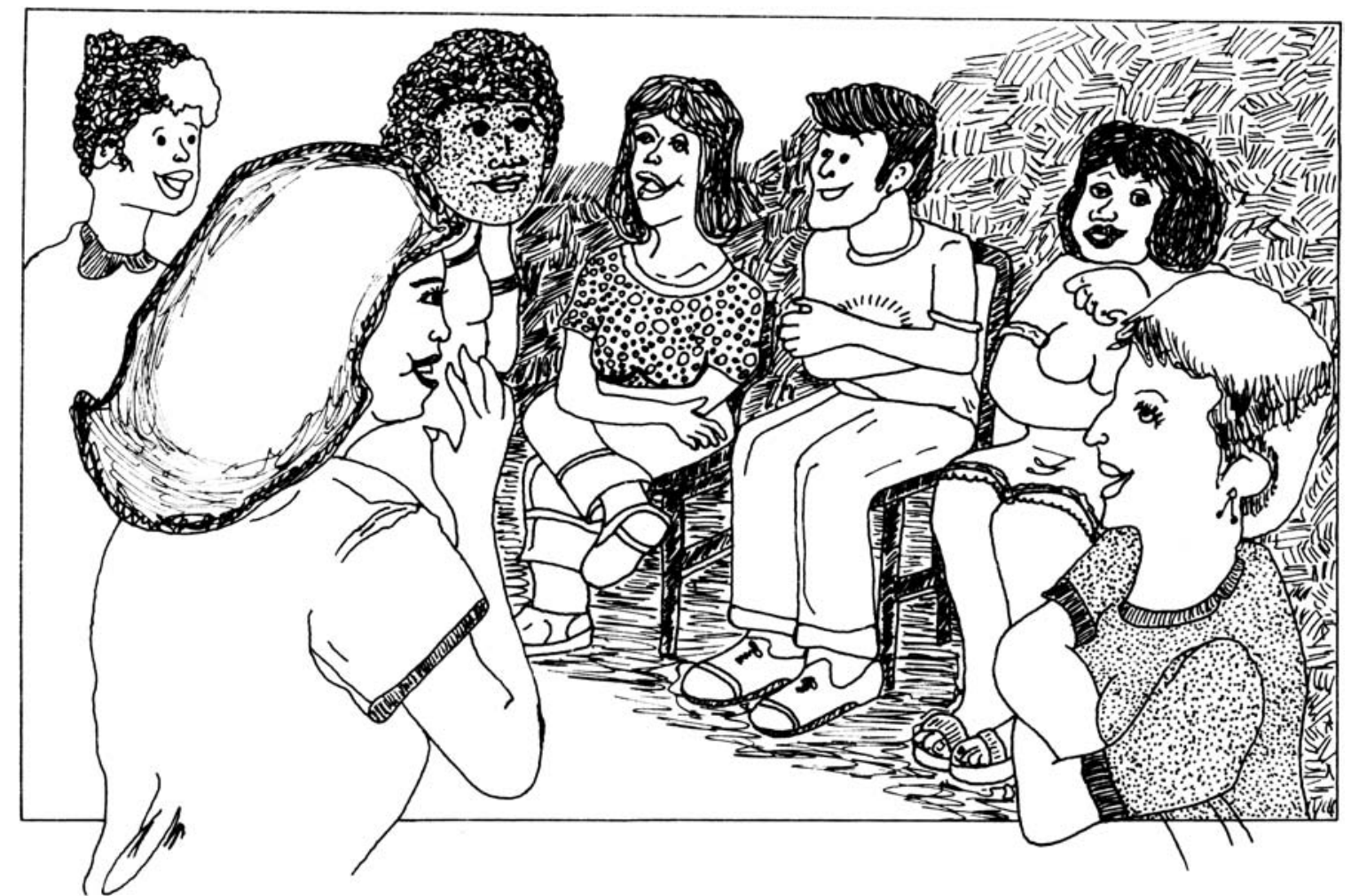

Os exames são realizados em sala de aula ou em área reservada para tal. $\mathrm{O}$ professor relaciona os resultados obtidos com o comportamento dos escolares em sala de aula.

$O$ instrumento utilizado para aferir a acuidade visual é a Escala Optométrica de Snellen, distribuida pelo PRESCE, que apresenta os resultados em percentual de visão de 10 a $100 \%$.

Para que se tenha uma idéia dos resultados da aferição de acuidade visual, levantou-se dados de escolas do Módulo da Bela Vista, onde foram examinados 5.809 escolares .(Tabela 1).

Resolveu-se agrupar as idades em intervalos de três em três anos para facilitar o tra-

balho de computação dos dados obtidos com o exame. Os percentuais foram agrupados de acordo com o tipo de encaminhamento a ser feito após a realização do teste, uma vez que o trabalho precípuo do Programa é de conscientização da comunidade, para ir em busca da resolução do problema detectado.

Considera-se que o escolar que apresenta visão menor que $30 \%$ deva receber um encaminhamento urgentíssimo e que, os situados na faixa de $40-50 \%$. tenham urgência também no encaminhamento. Os escolares com o percentual de visão entre 60 e $90 \%$ recebem encaminhamento sem urgência. Propositadamente deixou-se a coluna de $100 \%$ para estabelecer comparação com a visão normal².

TABELA 1 - Exame de acuidade visual de escolares do $10^{\circ}$ grau (séries iniciais), segundo grupos etários, em escolas do módulo 03, Bela Vista, Fortalє:za, 1982-83..

\begin{tabular}{|c|c|c|c|c|c|c|c|c|c|}
\hline \multirow{3}{*}{ Grupos etários } & \multirow{3}{*}{$\begin{array}{c}\text { Escolares } \\
\text { examinados }\end{array}$} & \multicolumn{8}{|c|}{ Acuidade visual $(\%)$} \\
\hline & & \multicolumn{2}{|c|}{$\leqslant 30$} & \multicolumn{2}{|c|}{$40-50$} & \multicolumn{2}{|c|}{$60-90$} & \multicolumn{2}{|c|}{100} \\
\hline & & N. ${ }^{\circ}$ & $\%$ & N. ${ }^{\circ}$ & $\%$ & N. ${ }^{\circ}$ & $\%$ & N. & $\%$ \\
\hline $\begin{array}{r}6-8 \\
9-11 \\
12-14\end{array}$ & $\begin{array}{l}1.672 \\
2.897 \\
1.240\end{array}$ & $\begin{array}{l}36 \\
90 \\
29\end{array}$ & $\begin{array}{l}2,16 \\
3,11 \\
2,34\end{array}$ & $\begin{array}{r}89 \\
231 \\
78\end{array}$ & $\begin{array}{l}5,32 \\
7,97 \\
6,29\end{array}$ & $\begin{array}{r}997 \\
1.466 \\
533\end{array}$ & $\begin{array}{l}59,63 \\
50,60 \\
43,98\end{array}$ & $\begin{array}{r}550 \\
1.110 \\
600\end{array}$ & $\begin{array}{l}32,89 \\
38,32 \\
49,39 \\
\end{array}$ \\
\hline Total & 5.809 & 155 & 2,67 & 398 & 6,85 & 2.996 & 51,58 & 2.260 & 38,90 \\
\hline
\end{tabular}

Os dados expostos na Tabela 1 mostram que, dos escolares submetidos ao teste de acuidade visual, apenas 2.260 apresentam capacidade visual igual a $100 \%$. Nota-se que, no

grupo de seis a oito anos $67,11 \%$ dos escolares apresentam deficiência visual em torno de $0-90 \%$. Comparando-se este grupo com os outros dois, observa-se que, $o$ percentual de 
escolares com deficiência visual diminuiu progressivamente, atingindo $61,68 \%$ no grupo de nove a onze anos e $51,61 \%$ no grupo de doze a catorze anos.

Supõe-se que este aumento progressivo da capacidade visual, se deva a erros quanto à capacidade de concentração e pouca coordenação motora dos escolares da alfabetização e primeira série, além das falhas que possam ocorrer quando da aplicação do teste. Deve-se levar ainda em consideração, que alguns problemas detectados chegam a autocura.

De acordo com os resultados obtidos por ocasião da aplicação dos testes, a professora deve entrar em contato com a família do escolar que apresentou deficiência visual e/ou auditiva para encaminhá-lo aos serviços médicos (Anexos 1 e 2, folhas de comunicado). Após alguns dias do comunicado, o professor apraza um encontro na escola com os pais dos escolares que apresentaram problemas. Nesta oportunidade, a enfermeira leva os pais a uma reflexão sobre a importância de dar continuidade à atividade iniciada pela professora.

Os resultados dos exames são anotados na ficha de saúde, assim como a providência adotada pelo pai frente aos problemas detectados.

A Tabela 2 apresenta os resultados dos encaminhamentos feitos após a realização do teste de acuidade visual nos 5.809 escolares.

Observa-se que dos 3.549 encaminhados aos serviços of talmológicos, compareceram 1.656 escolares, o que corresponde a $46,63 \%$.

Nota-se ainda que, apenas 941 estão fazendo uso do óculos e 214 foram submetidos a outros tipos de terapia. Deve-se ressaltar que, alguns escolares que compareceram ao oftalmologista tiveram prescrição de óculos e outros tratamentos (exercícios ortóticos e medicamentos).

Com relação à acuidade auditiva, de 5.809 alunos examinados, 3,07\% deles têm deficiência. Utiliza-se a mesma estratégia da acuidade visual, reunindo pais para encaminhá-los aos serviços de saúde.

Identificados os proble mas de visão e audição nos escolares, o professor procura melhor localizá-los em sala de aula, além de incentivar a leitura labial aos deficientes auditivos.

No ano de 1983, além de se implementar atividades implantadas nos anos anteriores, ênfase especial é dada aos dois itens abaixo.

\section{Encontro de avaliação}

Os encontros de avaliação dentro de metodologia participativa, congregam professores

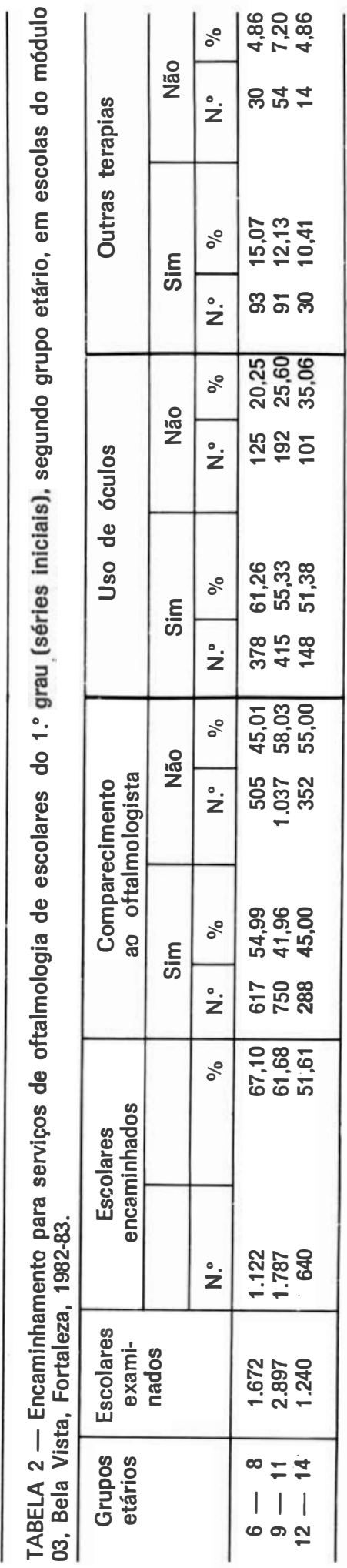


de diferentes escolas, com o intento não só de avaliar as ações, mas de proporcionar troca de experiências. Nesta oportunidade, cada participante fala um pouco de si, de seu trabalho e de suas dificuldades segundo os itens: - Quem sou eu; - De onde venho; - Como vejo o PRESCE; - O que faço e como faço; - Dificuldades (listar).

Quando todos terminam de falar, tem-se uma listagem dos problemas apresentados, que são agrupados e estudados em subgrupos na busca de soluções alternativas. Em seguida, volta-se ao grupão e discutem-se as soluções viáveis.

Após estes encontros, verificam-se mudanças significativas em algumas unidades escolares, como por exemplo, maior envolvimento dos professores nas ações educativas de saúde.

\section{Grupo de ajuda mútua}

Para formar e/ou dinamizar grupos de ajuda mútua reunem-se pais, com o objetivo de discutir os problemas de saúde e doęnça dos escolares. Durante esta reunião acontece a troca de experiência para a resolução dos prohlemas comuns.

A presença dos pais nas reuniões ainda não é constante, mas já se percebe o interesse deles em solicitar discussão de determinados assuntos, tais como alcoolismo, educação sexual, tóxicos, vacinação, relacionamento familiar, etc.

\section{CONCLUSÓES}

As enfermeiras desenvolvem um trabalho, visando a formação de hábitos para promoção e proteção específica da saúde individual e comunitária, respeitando o saber popular, crenças e tradições das famílias.

A escola penetra nos domicílios através da ação da criança, que orientada sobre saúde, multiplica entre companheiros e familiares, as noções aprendidas na escola.

O PRESCE vem contribuindo para o au- mento da demanda aos serviços de imunização, materno-infantil, of talmológicos, etc.

Os encontros de avaliação na metodologia participativa proporcionam uma reciclagem para os professores.

O material educativo distribuído pelo PRESCE fornece subsídios para a professora promover momentos de saúde com escolares e comunidade.

Nota-se ainda a dificuldade de envolvimento de alguns profissionais, no trabalho de ação comunitária.

Como Educação em Saúde é atividade que deve anteceder às ações básicas de saúde, considera-se que houve aquisição de hábitos favoráveis à saúde quando o escolar compreende a importância de sua participação voluntária e consciente como membro da comunidade na melhoria e na manutenção dos padrões de saúde; quando se consegue melhorar nível de participação comunitária; quando é ampliada a demanda às Unidades Sanitárias especialmente em função das ações preventivas.

\section{SUGESTÕES E RECOMENDAÇÕES}

Para garantir a continuidade do Programa, recomenda-se que:

- Haja formação de profissionais mais voltadas para o desenvolvimento de trabalho comunitário;

- Seja formado maior número de grupos de saúde para multiplicar entre os amigos e vizinhos os conteúdos adquiridos na escola;

- Os serviços de saúde procurem desenvolver seu trabalho centrado nas necessidades da comunidade;

- Os pais se comprometam em multiplicar as informações entre os familiares e vizinhança;

- Sejam criados serviços of talmológicos a nível de unidade sanitária.

VILAR, M. C. P. de M. et alii. What the nurse of Health Secretary is doing for the school children.

Rev. Bras. Enf., Brasília, 37(1): 56-64, 1984.

\section{REFERENCIAS BIBLIOGRAFICAS}

1. BRASIL. Ministério da Educação e Cultura. Criança para criança. 2. ed. Brasília, 1981.

2. BRASIL. Ministério da Educação e Cultura. Secretaria Geral. Manual de orientação do professor na aplicação do teste de aferição da acuidade visual. Brasília, Departamento de Documentação e Divulgação, 1978.

3. BRASIL. Ministério da Saúde. Saude como compreensão de vida. Belo Horizonte, CS/MEC, s. d.

4. CEARA. Secretaria de Saúde do Estado. DCS/DT. Anteprojeto do programa de educação para a saude da Secretaria de Saude do Estado do Ceará. Fortaleza, 1979. 22 p. (Mimeografado).

5. CEARA. Secretaria de Saúde do Estado/ PRESCE. Ação normativa e metodológica. Fortaleza, 1980. $34 \mathrm{p}$.

6. CEARA. Secretaria de Saúde do Estado/PRESCE. Guia metodológico. Fortaleza, 1981.

7. CEARA. Sécretaria de Saúde do Estado. Programa de educação para a saúde escolar/comunitária. Fortaleza, 1980. 10 p. (Mimeografado).

8. CEARA. Secretaria de Saúde do Estado/PRES- 
CE. Relatório das atividades 1979 a 1982. Fortaleza, 1982. 29 p. (Mimeografado).

9. DERVILLE, L. M. T. Psicologia prática no ensino. 2. ed. São Paulo, IBRASA, 1978.

10. DORIN, L. Fsicologia da criança. Rio de Janeiro, Ed. Brasil, 1973.

11. FREIRE, P. Educação e conscientização. In: Educação como prática da liberdade. 12. ed. Rio de Janeiro, Paz e Terra, 1981. p. 101-22.

12. GALIOTTI, O. Noções de oftalmologia para pediatras. São Paulo, 1976.

13. JERSILD, A. T. Relações entre companheiros no fim da meninice. In: Psicologia da criança. Belo Horizonte, Itatiaia, 1971. p. 217-52.

14. LAMARE, R. de A vida de nossos filhos. São Paulo, Bloch, 1973.

15. LEAVELL, H. R. Outros serviços básicos de saúde. In: LEAVELL, H. R. \& CLARK, E. G. Medicina preventiva. São Paulo, McGraw-Hill do Brasil, 1977. p. 568-72.

16. SILVA, M. G. C. Situação de saúde em Fortaleza: análise através da mortalidade em 1978-80. Fortaleza, 1982.

\section{ANEXO 1 \\ Secretarias de Saúde/Educação do Estado do Ceará \\ Programa de educação em saúde escolar/comunitária \\ Comuniçado}

Data:...../..../.....

Com a aplicação do teste de acuidade visual, constatou-se que o aluno(a) $\ldots \ldots \ldots \ldots \ldots \ldots$

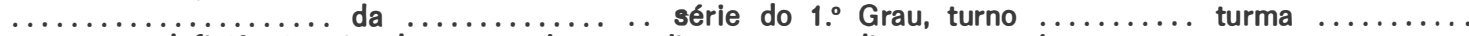
apresenta deficiência visual, que pode prejudicar seu rendimento escolar.

Solicitamos levá-lo ao oculista, para o exame, tendo em vista apresentar suspeita de alteração visual: $\mathrm{OD} \ldots \ldots . . \% \mathrm{OE} \ldots \ldots \%$ de visão.

Diretor ou professor

Observações:

Para efeito de atendimento do aluno no:

- INAMPS, IPEC ou IPM o pal ou responsável deverá apresentar o cartão de beneficiário.

- No Centro ou Posto de Saúde - Regis tro de Nascimento

O pai ou responsável deverá informar ao profes sor a conduta indicada pelo oculista.

- Unidade escolar:

- Pai ou responsável:

OBS.: - Favor devolver à escola.

\section{ANEXO 2 \\ Secretarias de Saúde/Educação do Estado do Ceará \\ Programa de educação em saúde escolar/comunitária \\ Comunicado}

Com a aplicação do teste de acuidade visual, constatou-se que o aluno(a) Data: $\ldots \ldots / \ldots \ldots / \ldots \ldots$ $\ldots \ldots \ldots \ldots \ldots \ldots \ldots$ da $\ldots \ldots \ldots \ldots \ldots$ série do $10^{\circ}$ Grau, turno $\ldots \ldots \ldots \ldots$ turma $\ldots \ldots \ldots \ldots$ apresenta deficiência auditiva que pode prejudicar seu rendimento escolar.

Solicitamos levá-lo(a) ao médico de ouvido, para um exame, tendo em vista apresentar suspeita de alteração auditiva no ouvido ( ) Direito

( ) Esquerdo.

Observações:

Diretor ou professor

Para efeito de atendimento do aluno no:

- INAMPS, IPEC ou IPM o pai ou respons ável deverá apresentar o cartão de beneficiário.

- No Centro ou Posto de Saúde - Regis tro de Nascimento

O pai ou responsável deverá informar ao profes sor, a conduta indicada pelo médico

- Unidade escolar:

- Pai ou responsável:

OBS.: - Favor devolver à escola.

64 - Rev. Bras. Enf., Braslia, 37(1), jan./fev./mar., 1984 